\title{
A study of conservative management of tibial plateau fractures
}

\author{
Robin Shrestha, Manoj Kandel, Hemant Kumar Gupta, Sundar Kumar Shrestha, Sagun Dongol, \\ Rajkumar Ravi Hamal \\ Department of Orthopedics, College of Medical Sciences Bharatpur, Nepal
}

\author{
Correspondence \\ Dr. Robin Shrestha \\ Lecturer, \\ Department of Orthopedics, \\ Purbanchal University College of \\ Medical and Allied Sciences, \\ Gothgaon, Morang \\ Email: \\ dr.robinshrestha@gmail.com
}

DOI: http://dx.doi.org/10.3126/ jemsn.v12i1.14455

\begin{abstract}
Background \& Objectives: Tibial plateau fractures have been studied and reported extensively and exhaustively but still controversy exists over its management, whether surgical or conservative. Although several methods of treatment have been devised, each method of treatment offers their own advantages and disadvantages. In this study we utilized conservative method which like any other mode of treatment restores articular congruity, axial alignment, joint stability, functional motion and avoids complications. This study was conducted with an objective to evaluate the functional and radiological outcome of conservative treatment. Materials \& Methods: Forty two randomly selected cases of tibial plateau fracture in adults more than 20 years of age were treated with above knee plaster of Paris cast for 4 to 6 weeks. At the end of six months outcome of this study was analyzed by Modified Rasmussen clinical criteria and radiological evaluation. Results: The Clinical assessment showed that $48 \%$ had excellent, $28 \%$ had good, $10 \%$ had fair and $14 \%$ had poor outcome while radiological outcome of this study showed $40.5 \%$ excellent, $33.3 \%$ fair, $9.5 \%$ fair and $16.7 \%$ poor result. Conclusion: In appropriately selected cases conservative treatment is a reliable alternative and is certainly without the complications associated with surgery.

Key words: Articular depression; Modified Rasmussen clinical criteria; Tibial plateau fracture
\end{abstract}

Citation: Shrestha R, Kandel M, Gupta HK, Shrestha SK, Dongol S, Hamal RR. A study of conservative management of tibial plateau fractures. JCMS Nepal. 2016;12(1):5-9.

\section{INTRODUCTION}

More than 1000 articles, thesis and books have documented the trials and tribulations of treating these capricious joints. ${ }^{1,2}$ The more interesting fact is excellent results have been published in both groups which gives definitive conclusion of not all fractures of the proximal tibial articular surface require surgery and not all displaced intra-articular fractures need to be surgically reduced. ${ }^{3}$ Various treatment methods have been used for years with varying results that ranges from traction, ${ }^{4}$ closed treatment with bracing, ${ }^{5,6}$ external fixation, ${ }^{7}$ percutaneous screw fixation to open reduction and internal fixation ${ }^{9-12}$ with various devices .

The proximal tibial articular surface can tolerate modest amount of articular displacements and in meticulously selected cases, non-operative treatment will result in excellent outcomes despite some articular irregularities. Therefore non operative treatment is indicated for tibial plateau fractures that will heal without a significant deformity or for elderly patients or patients with associated medical problems where operative intervention is not an option. Localized depressions of up to 10 millimeters in the articular surface of lateral plateau may result in stable knees and have good outcomes when treated non- operatively. ${ }^{13}$

This interventional and prospective study was conducted in minimally displaced and depressed tibial plateau fracture with displacement of less than $4 \mathrm{~mm}$, depression of less than $8 \mathrm{~mm}$ and less than 10 degrees of instability to evaluate the functional outcome and complications of conservative treatment.

\section{MATERIALS AND METHODS}

This interventional and prospective study included forty- two randomly selected cases of tibial plateau fracture in adults more than 20 years of age who presented in the Department of Orthopedics, College of Medical Sciences, Bharatpur, Chitwan, Nepal from August 2012 to July 2014 and treated with conservative method.

\section{Inclusion criteria}


Table 1: Clinical Assessment

\begin{tabular}{|c|c|c|}
\hline CLINICAL ASSESSMENT & $\begin{array}{l}\text { NO. OF } \\
\text { PATIENTS }\end{array}$ & $\%$ \\
\hline \multicolumn{3}{|l|}{ PAIN } \\
\hline None & 15 & 35.7 \\
\hline Occasional & 18 & 42.9 \\
\hline $\begin{array}{l}\text { Stabbing pain in certain } \\
\text { position }\end{array}$ & 6 & 14.3 \\
\hline Constant pain after activity & 3 & 7.1 \\
\hline \multicolumn{3}{|l|}{ WALKING CAPACITY } \\
\hline $\begin{array}{l}\text { Normal walking capacity for } \\
\text { age }\end{array}$ & 17 & 40.5 \\
\hline $\begin{array}{l}\text { Walking outdoor more than } \\
\text { one hour }\end{array}$ & 16 & 38.1 \\
\hline Walking outdoor 15 mins & 8 & 19.0 \\
\hline Walking indoor only & 1 & 2.4 \\
\hline \multicolumn{3}{|l|}{ KNEE EXTENSION } \\
\hline Normal & 32 & 76.2 \\
\hline Lack of extension $<10$ degree & 7 & 16.7 \\
\hline Lack of extension $>10$ degree & 3 & 7.1 \\
\hline \multicolumn{3}{|l|}{ KNEE FLEXION } \\
\hline Full & 29 & 69.0 \\
\hline At least 120 degree & 9 & 21.4 \\
\hline At least 90 degree & 4 & 9.5 \\
\hline \multicolumn{3}{|l|}{ POWER OF QUADRICEPS } \\
\hline Grade 5 & 28 & 66.7 \\
\hline Grade 3-4 & 14 & 33.3 \\
\hline \multicolumn{3}{|l|}{ STABILITY } \\
\hline $\begin{array}{l}\text { Normal in extension and } 20 \\
\text { degree flexion }\end{array}$ & 28 & 66.7 \\
\hline $\begin{array}{l}\text { Abnormal instability in } 20 \\
\text { degree flexion }\end{array}$ & 8 & 19.0 \\
\hline $\begin{array}{l}\text { Instability in extension }<10 \\
\text { degree }\end{array}$ & 6 & 14.3 \\
\hline
\end{tabular}

Table 3: Correlation between articular depression and clinical result

\begin{tabular}{lccccc}
$\begin{array}{l}\text { Articular } \\
\text { Depression }\end{array}$ & EXCELLENT & GOOD & FAIR & POOR & Total \\
\hline NONE & 15 & 1 & 0 & 0 & 16 \\
\hline$<$ 5MM & 5 & 11 & 1 & 1 & 18 \\
\hline 6-10MM & 0 & 0 & 3 & 3 & 6 \\
\hline$>$ 10MM & 0 & 0 & 0 & 2 & 2 \\
\hline Total & 20 & 12 & 4 & 6 & 42 \\
\hline
\end{tabular}

Table 2: Radiological Assessment

\begin{tabular}{lcc}
$\begin{array}{l}\text { RADIOLOGICAL } \\
\text { ASSESSMENT } \\
\text { Condylar widening }\end{array}$ & $\begin{array}{c}\text { NO. OF } \\
\text { PATIENTS }\end{array}$ & $\mathbf{\%}$ \\
NONE & 13 & 31.0 \\
<5MM & 24 & 57.1 \\
6-10MM & 3 & 7.1 \\
>10MM & 2 & 4.8 \\
\hline Varus valgus angulation & & \\
NONE & 20 & 47.6 \\
<10 DEGREE & 15 & 35.7 \\
10-20 DEGREE & 5 & 11.9 \\
>20 DEGREE & 2 & 4.8 \\
Articular depression & & \\
NONE & 16 & 38.1 \\
<5MM & 18 & 42.9 \\
6-10MM & 6 & 14.3 \\
>10MM & 2 & 4.8 \\
Osteoarthrosis & & \\
NONE/ NO & & 40.5 \\
PROGRESS & 17 & 50.0 \\
GROGRESSION BY & 21 & 9.5 \\
PROGE 1 & & \\
> GRADE 1 & 4 & \\
\hline
\end{tabular}

1. None displaced split stable fracture.

2. Minimally displaced and depressed fracture with displacement of $<4 \mathrm{~mm}$, depression of $<8 \mathrm{~mm}$. and $<10$ degree of instability.

3. Sub-meniscal rim fractures.

4. Fractures in elderly, osteoporotic patients and low demands for surgery.

5. Pathological fracture.

\section{Exclusion criteria}

1. Patients who have been diagnosed as closed unstable tibial plateau fracture.

2. Compound fracture Gustilo Anderson type II and III.

3. Fracture associated with ipsilateral femur, tibia and foot fracture.

All the cases meeting the above mentioned criteria were treated with above knee plaster of paris (POP) cast. The range of movement, extensor lag and valgus and varus deformity of the knee were measured and check X-ray was done at the time of cast bracing. Cast was continued for 4 to 6 weeks depending upon radiological sign of union. Early active and passive ROM of knee joint was started 


\begin{tabular}{|c|c|c|c|c|c|}
\hline \multirow{2}{*}{$\begin{array}{l}\text { Clinical } \\
\text { result }\end{array}$} & \multicolumn{4}{|c|}{ Radiological result } & \multirow{2}{*}{ Total } \\
\hline & EXCELLENT & GOOD & FAIR & POOR & \\
\hline $\begin{array}{c}\text { EXCEL } \\
\text { LENT }\end{array}$ & 14 & 20 & 4 & 0 & 20 \\
\hline GOOD & 3 & 12 & 7 & 0 & 12 \\
\hline FAIR & 0 & 4 & 2 & 2 & 4 \\
\hline POOR & 0 & 6 & 1 & 5 & 6 \\
\hline Total & 17 & 42 & 14 & 7 & 42 \\
\hline
\end{tabular}

immediately after removal of cast. Patients were allowed toe- touch walking, partial, near- total and total weight bearing depending upon radiological features and clinical improvement of injured knee. At the end of six months outcome of this study was analyzed by Modified Rasmussen clinical criteria and radiological evaluation. ${ }^{14}$

All the statistical operations were done through SPSS for Windows, Version 22.0

\section{RESULTS}

The youngest patient in this study was 20 years, the oldest was 88 years and mean age was 44.9 years. There were $29(69 \%)$ male and $13(31 \%)$ female. Twenty four $(57.1 \%)$ patients sustained injury secondary to road traffic accident, seven (16.7\%) due to fall from height, three $(7.1 \%)$ due to fall from stairs, seven $(16.7 \%)$ due to slip on the floor and one $(2.4 \%)$ due to physical assault. In this study 24 patients $(57.1 \%)$ sustained Schatzker type 1, eight (19\%) Schatzker type 2, three (7.1\%) Schatzker type 3, two (4.8\%) Schatzker type 5 and four $(11.9 \%)$ Schatzker type 6 fractures. The right knee was injured in $30(71.4 \%)$ and left knee in 12 (28.6\%) patients.

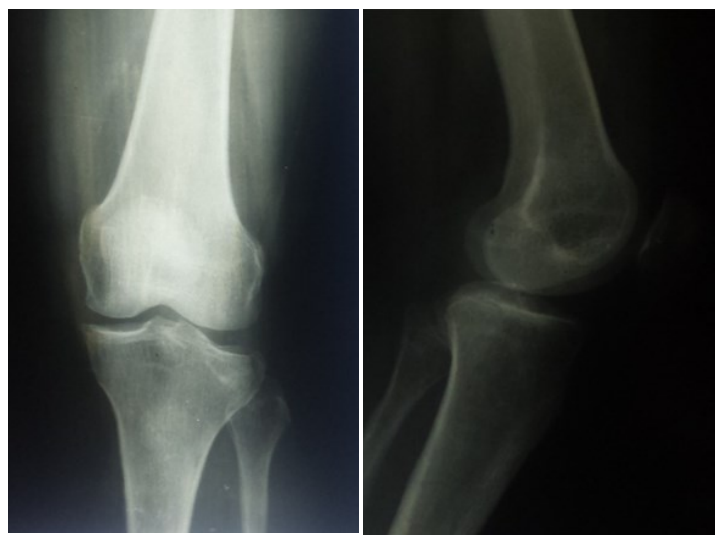

Fig 1: Tibial plateau fracture
The clinical and radiological results are tabulated in the tables 1 and 2 .

Overall clinical evaluation of this six months regular follow up study showed 20 (48\%) excellent, $12(28 \%)$ good, four $(10 \%)$ fair and six (14\%) poor outcome. In overall this study showed $86 \%$ satisfactory result. $(\mathrm{p}$ value $=0.002)$

Overall radiological outcome of this study showed 17 (40.5\%) excellent, four (9.5\%) good 14 (33.3\%) fair, and $7(16.7 \%)$ poor result. This data showed almost $84 \%$ of satisfactory outcome. ( $p$ value $=$ $0.000)$

We found that 27 out of 34 patients with articular depression of $5 \mathrm{~mm}$ or less had excellent or good clinical result and all the eight patients with articular depression of $6 \mathrm{~mm}$ or more had fair or poor clinical result (Table 3 ).

Out of 32 patients who had excellent or good clinical result, 21 had excellent or good radiological result and out of 21 patients with fair or poor radiological result, 10 had fair or poor clinical result (Table 4).

\section{DISCUSSION}

The Tibial plateau fractures constitute approximately $1 \%$ of all fractures. ${ }^{15}$ Fractures of the tibial plateau are caused by a combination of varus or valgus force with axial loading which leads to malalignment, depressed articular surface and high risk of osteoarthritis. ${ }^{16,17}$ Sir Astley Cooper was the first to publish his method of treatment of tibial plateau fractures in $1825 .{ }^{18}$ Apley stressed on early joint rehabilitation and developed successful methods of traction that permitted early range of motion of joints while maintaining sufficient immobilization for fracture union and reported satisfactory results in the tibial plateau fractures as compared with the results of surgery. ${ }^{19,20}$

In our study we found that tibial plateau fractures

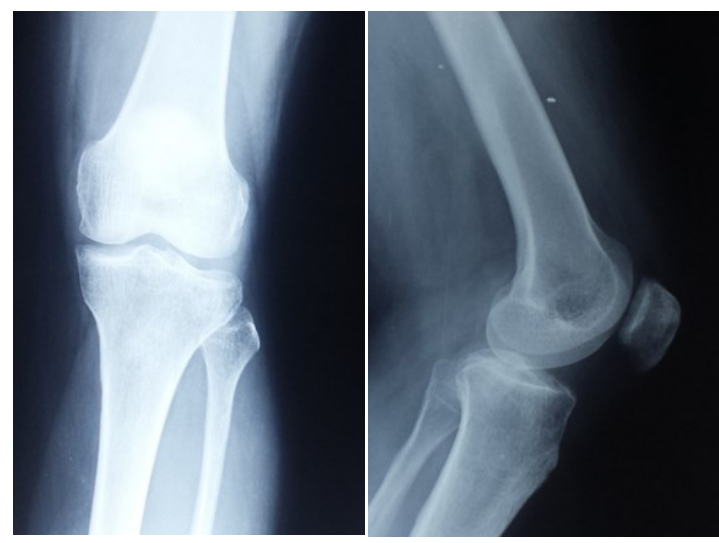

Fig 2: Tibial plateau fracture at 6 weeks 


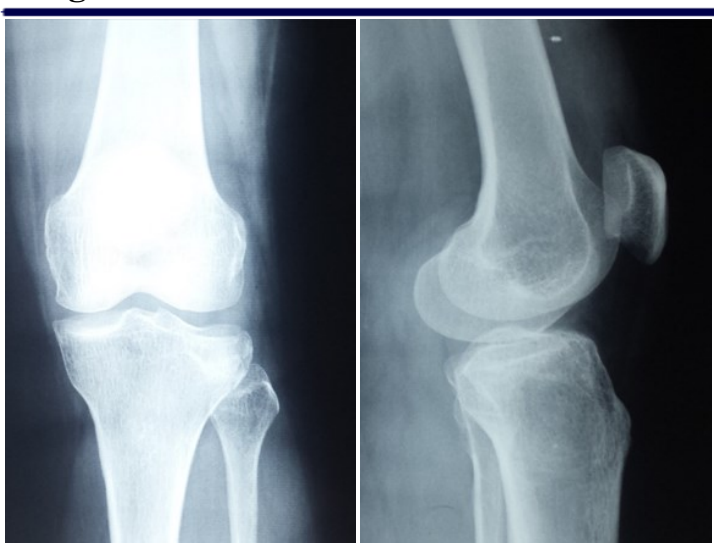

Fig 3: Tibial plateau fracture at 6 months

were more common in active phase of life and in males. Road traffic accident, fall from height and slip on floor were the common modes of injury and type I and II fractures were more common than type III, IV, V and VI. Duration of hospitalization was more in fractures associated with large swelling, associated other injuries treated with skeletal traction and elderly patient with significant soft tissue injuries and other co-morbid conditions.

Like our study, various other studies have shown that there is a direct co-relation between articular depression and clinical outcome. ${ }^{5,14,21}$ In our study many patients with less than satisfactory roentgenographic results had good to excellent functional results which correlated with a study done by Duwaliuss and Connoly ${ }^{22}$ who concluded that observations based on roentgenographic examinations did not correlate with the functional end results.

Tibial plateau fracture treated by closed reduction and immobilization for six weeks in a well moulded cast have resulted in acceptable functional and clinical results in different studies. ${ }^{16,23,24}$

The strength of this study is the standardized and scientific manner in which the procedure was carried out. The limitations of this study include the length of the study and it being a single cohort study with no matched comparative groups of other techniques included.

\section{CONCLUSION}

Hence we can conclude that overall clinical and radiological results are acceptable in tibial plateau fractures treated conservatively. Various intraoperative and post-operative complications along with burden of re-operation for implant removal are not expected with conservative management. So it is still a reliable, inexpensive and alternative treatment option in undisplaced and minimally displaced fractures and fracture in osteoporotic bones with associated co-morbid body conditions.

\section{REFERENCES}

1. Andrew F, John CP, Robert V. Treatment of tibial plateau fractures. CurrOpinOrthop. 2007; 18(1):49-53. DOI: 10.1097/BCO.0b013e3280119613.

2. Stevens DG, Beharry R, McKee MD, Waddell JP, Schemitsch EH. The long-term functional outcome of operatively treated tibial plateau fractures. Journal of orthopaedic trauma 2001;15(5):312-20. DOI: 10.1097/00005131-200106000-00002. PMID:1143313

3. Phillip BB. Knee injuries. In: Canale ST, BeatyJH, Daughterty K, editors. Campbell Operative Orthopaedics. 11 th ed. New York: Mosby Elsevier; 2008. p. 2395-522.

4. Apley AG. Fractures of the lateral tibial condyle treated by skeletal traction and early mobilisation; a review of sixty cases with special reference to the long-term results. J Bone Joint Surg Br. 1956;38-B(3):699-708. PMID:13357593.

5. DeCoster TA, Nepola JV, el-KhouryGY. Cast brace treatment of proximal tibia fractures. A ten-year followup study. ClinOrthopRelat Res. 1988(231):196-204. PMID:3370874.

6. Jensen DB, Rude C, Duus B, Bjerg-Nielsen A. Tibial plateau fractures. A comparison of conservative and surgical treatment. J Bone Joint Surg Br. 1990;72(1):4952. PMID:2298794.

7. Canadian Orthopaedic Trauma S. Open reduction and internal fixation compared with circular fixator application for bicondylartibial plateau fractures. Results of a multicenter, prospective, randomized clinical trial. J Bone Joint Surg Am. 2006; 88(12):2613-23. DOI: 10.2106/JBJS.E.01416. PMID:17142411.

8. Koval KJ, Sanders R, Borrelli J, Helfet D, DiPasquale T, Mast JW. Indirect reduction and percutaneous screw fixation of displaced tibial plateau fractures. J Orthop Trauma. 1992;6(3):340-6. DOI: 10.1097/00005131199209000-00012. PMID:1403254.

9. Young MJ, Barrack RL. Complications of internal fixation of tibial plateau fractures. Orthop Rev. 1994; 23 (2):149-54. PMID:8196973.

10. Barei DP, Nork SE, Mills WJ, Coles CP, Henley MB, Benirschke SK. Functional outcomes of severe bicondylartibial plateau fractures treated with dual incisions and medial and lateral plates. J Bone Joint Surg Am. 2006;88(8):1713-21. DOI: 10.2106/JBJS.E.00907. PMID:16882892.

11. Barei DP, Nork SE, Mills WJ, Henley MB, Benirschke SK. Complications associated with internal fixation of high-energy bicondylartibial plateau fractures utilizing a two-incision technique. J Orthop Trauma. 2004;18 (10):649-57. DOI: 10.1097/00005131-200411000-00001. PMID: 15507817.

12. Ebraheim NA, SabryFF, Haman SP. Open reduction and internal fixation of 117 tibial plateau fractures. J orthop trauma. 2004;27(12):1281- 7 .

13. Hohl M. Managing the challenges of tibial plateau fractures. J Musculoskel Med. 1991;8:70-86.

14. Rasmussen PS. Tibial condylar fractures: Impairment of knee joint stability as an indication for surgical treatment. J Bone Joint Surg (Am). 1973;55(A):1331-50.

15. Rademakers MV, KerkhoffsGMMJ, Sierevelt IN, RaaymakersELFB, Marti RK. Operative Treatment of 109 Tibial Plateau Fractures: Five- to 27-Year Follow-up 
Results. J Orthop Trauma. 2007; 21(1): 5-10. DOI: 10.1097/BOT.0b013e31802c5b51. PMID:17211262.

16. Honkonen SE. Degenerative arthritis after tibial plateau fractures. J Orthop Trauma. 1995;9(4):273-7. DOI: 10.1097/00005131-199509040-00001. PMID:7562147.

17. Lansinger O, Bergman B, Korner L, Andersson GB. Tibial condylar fractures. A twenty-year follow-up. . J Bone Joint Surg Am. 1986;68(1):13-9. PMID:3941115

18. Raikin S, Froimson MI. Combined limited internal ficxation with circular frame external fixation of intra articular tibial fracture. Othopedics. 1999; 22(11):101925.

19. Schulak DJ, Gunn DR. Fractures of tibial plateaus. A review of the literature. ClinOrthopRelat Res. 1975 (109):166-77. DOI: 10.1097/00003086-19750600000025. PMID: 1093768.

20. Apley AG. Fractures of the tibial plateau. OrthopClin North Am. 1979; 10(1):61-74. PMID:450404.

21. Scotland T, Wardlaw D. The use of cast-bracing as treatment for fractures of the tibial plateau. J Bone Joint Surg( Br). 1981;63B:575-8.

22. Duwelius PJ, Connolly JF. Closed reduction of tibial plateau fractures: A comparison of functional and roentgenographic end results. Clin Orthop Relat Res. 1988:116-26. DOI: 10.1097/00003086-198805000-00011.

23. Delamater R, Hohl M. The cast brace and tibial plateau fractures. Clin Orthop Relat Res. 1989; 26-31.

24. Drennan DB, Locher FG, Maylahn DJ. Fractures of the tibial plateau: Treatment by closed reduction and spica cast. J Bone Joint Surg (Am). 1979;61(A):989-95. 